\section{Libro Hematología. Diagnóstico y Terapéutica. Adultos y niños}

\section{Sr. Editor}

El 2 de mayo de 2019 ocurrió el lanzamiento del Libro "Hematología. Diagnóstico y Terapéutica. Cuarta Edición 2019, 608 páginas, Editorial Mediterráneo, Santiago de Chile y Buenos Aires, impreso en Eslovenia. ISBN 978-956-220-413-2.

Editor: Guido Osorio; Coeditores: Dres.(a) Lautaro Vargas, María Elena Cabrera, Diego Mezzano.

El objetivo de este texto, como lo señalan sus autores, ha sido crear un libro de consulta de fácil lectura, con esquemas docente que sean de utilidad para los distintos estudiantes y profesionales de la salud.

El contenido incluye todo el espectro de la Hematología, desde la patología del eritrocito, leucocito y plaquetas, hasta el aporte de nuevas técnicas de apoyo al diagnóstico y tratamiento.

Su originalidad estriba en que es el único libro de Hematología a nivel mundial que une o separa las patologías hematológicas del niño y del adulto en un solo texto.

Los puntos fuertes son un enfoque simple, acorde a la realidad chilena y extrapolable al resto de los países latinoamericanos de habla española, con experiencias locales, basadas en la medicina con evidencia. En este sentido ha sido exportado a Argentina, Colombia, Ecuador, España, México, Panamá, Paraguay, Perú y Uruguay.

Su utilidad queda de manifiesto al leerlo como un texto de consulta ameno, de fácil lectura, aplicable a la actividad diaria de un profesional de la salud.

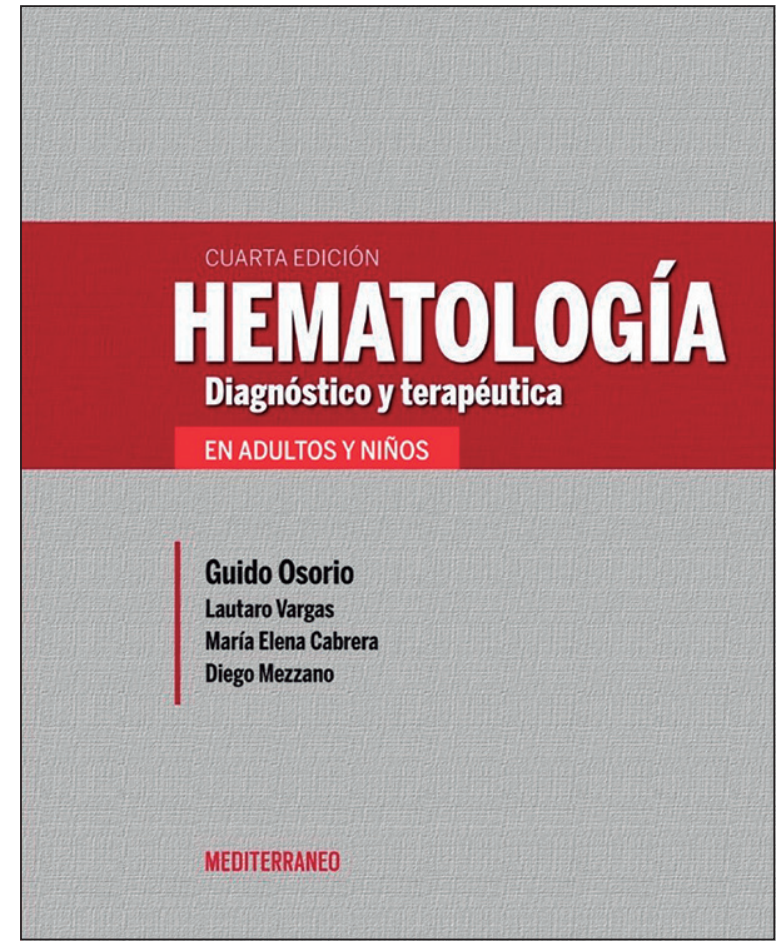

Va dirigido a alumnos de medicina, internos, becados de medicina y pediatría, médicos generales, médicos internistas, pediatrías. También a otros profesionales de la salud, como enfermeras o tecnólogos médicos y en general para el equipo profesional de apoyo médico, que necesita profundizar sus conocimientos de Hematología.

En esta nueva edición, el libro ha experimentado cambios profundos respecto a la tercera edición y contiene actualización de diagnóstico y tratamiento en un período de 11 años. Nuevos capítulos, exponen la aplicación de inmunohistoquímica, genética, biología molecular, farmacología oncológica, técnicas y procedi-

Correspondencia:

Guido Osorio S.

gosorios77@hotmail.com 
mientos de avanzada, terapias innovadoras, sin olvidar la radioterapia, el trasplante de médula ósea en niños y adultos y las novedades en el campo de la Hemostasia y la Medicina transfusional. Las Figuras, cuadros y tablas clínicas destacan por su colorido y ayudan a la comprensión de los temas expuestos.

Al final de cada capítulo un experto en preguntas de múltiple elección convoca al lector a cuestionarse sobre el tema y clarificar lo esencial de cada capítulo.

En resumen, se espera una buena acogida nacional e internacional a este texto de los escasos en esta materia en habla hispana que corresponde a cursos y asignaturas que cubrirían la formación en Medicina Interna en general y en la subespecialidad de Hematología en Pediatría y Medicina de Adultos.

Guido Osorio S. ${ }^{a}$ ${ }^{a}$ Editor del libro Hematología. Diagnóstico y Terapéutica. Adultos y niños 